\title{
A Tethered Cord with Hemivertebra: A Case Report and Review of Literature
}

\author{
Kiyasettin Asil ${ }^{1}$, Mahizer Yaldiz ${ }^{2}$, Can Yaldiz ${ }^{3}$, Birol Ozkal ${ }^{4}$ \\ Departments of ${ }^{1}$ Radiology, ${ }^{2}$ Dermatolgy, ${ }^{3}$ Neurosurgery, Sakarya Training and Research Hospital, Sakarya, \\ ${ }^{4}$ Department of Neurosurgery, Alanya Hospital, Antalya, Turkey
}

Spinal dysraphisms are defined as open and closed dysraphisms. A hemivertebra is a congenital condition seen in $61 \%$ of patients with congenital anomalies. The first report of the excision of a hemivertebra was by Royle in 1928. A sixteenyear-old girl was admitted to our clinic with a congenital stain on the waist and a normal neurological examination. No new cases have been reported in recent literature. Our case, which is also rare, is associated with a tethered cord only and no other congenital abnormalities.

Key Words: Tethered cord $\cdot$ Hemivertebra $\cdot$ Nevus flammeus

\section{INTRODUCTION}

Spinal cord development results from consecutive gastrulation, primary neurulation, secondary neurulation, and retrogressive differentiation periods. Defects in early embryonic periods lead to spinal dysraphisms, which include open spinal dysraphism and closed spinal dysraphism covered by skin. Neuroenteric cysts, split cord malformations, dermal sinus, caudal regression, segmental spinal dysgenesis, thick filum terminale, filar and intradural lipomas, and terminal ventricle are located within the spinal dysraphisms ${ }^{1,5,9,12)}$.

The first report of the excision of a hemivertebra (HV) was by Royle in 1928P. HV is a congenital condition seen in $61 \%$ of patients with anomalies. It displays its most important clinical feature with progressive congenital scoliosis ${ }^{3,4,6-8,10,11)}$. Asymptomatic cases are numerous.

Tethered cord syndrome (TCS) encompasses a group of diseases that include the stretching of the spinal cord due to congenital or acquired causes; these diseases are characterized by progressive neurologic losses. The most common causes of TCS include split cord syndrome (17.0-38.2\%), lipomyelomeningocele (19.1-94.1\%), short and thick filum terminale (5.8-

\footnotetext{
- Received: May 27, 2015 - Revised: August 20, 2015

- Accepted: August 20, 2015

Corresponding Author: Can Yaldiz, MD

Department of Neurosurgery, Sakarya Training and Research Hospital, Sakarya, 54010, Turkey

Tel: +900503572222, Fax: +902643460101

E-mail: drcanyaldiz@yahoo.com

@This is an Open Access article distributed under the terms of the Creative Commons Attribution Non-Commercial License (http://creativecommons.org/ licenses/by-nc/3.0/) which permits unrestricted non-commercial use, distribution, and reproduction in any medium, provided the original work is properly cited.
}

55.8\%), and the adherents occurring after operations for myelomeningocele (5.4-17.9\%). The clinic is formed by the stretching of the lumbosacral spinal cord segments due to the spinal canal and spinal cord having different growth capacities, $2,7,11,12$.

No new case has been reported in recent literature. Hemivertebrae deformation as diagnosed in our case is a rare entity even in clinical experience and literature, and it can cause rapid progression in tethered cord clinical presentation so that surgical treatment should be considered primarily.

\section{CASE REPORT}

A sixteen-year-old female was admitted to the dermatology clinic of our hospital with a congenital stain on the waist. Her medical history revealed previous treatment for repeated and frequent urinary tract infections. The patient complained of chronic low back and rectal pain only. A pink-red irregularly shaped macular lesion measuring $3 \times 5 \mathrm{~cm}$ was observed in the lumbosacral area upon dermatological examination. The lesion was considered a nevus flammeus (Fig. 1). She had no motor deficits, and her reflexes were normal on neurological examination. Lumbar magnetic resonance imaging (MRI) revealed that the conus medullaris was extending up to the level of the L4 vertebrae on the sagittal T2-W series, and it appeared fixed to the posterior laminal face (Fig. 2). An HV was observed in the L5 vertebrae on the lumbar computerized tomography (CT), but spur formation extending into the spinal canal was not detected (Fig. 3). A hyperreflexic bladder was observed in the patient during an urodynamic evaluation. Abdominal ultrasonography was unremarkable. There were no abnormalities on the chest or spinal radiographs other than HV.

After review of all examination results and after appropriate 


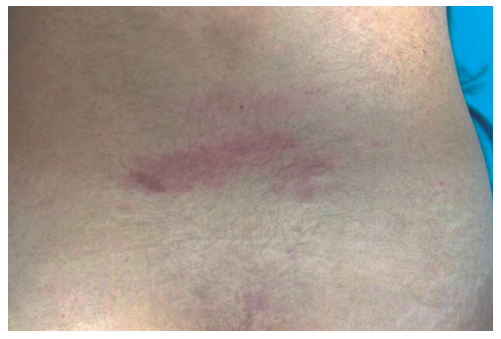

Fig. 1. Pink-red irregularly shaped, macular lesion $3 \times 5 \mathrm{~cm}$ in size was seen in the lumbosacral in dermatological examination. The lesion was considered as nevus flammeus.

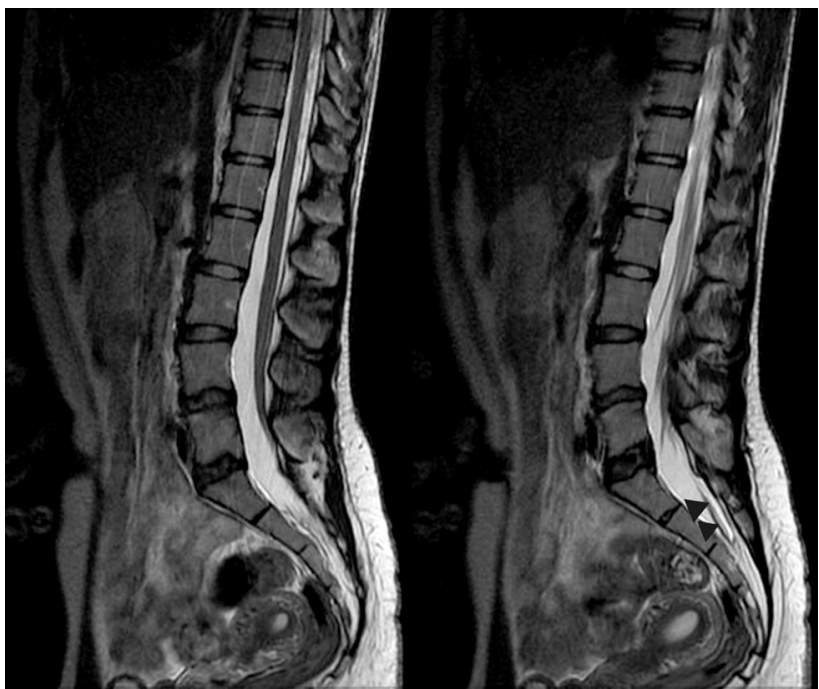

Fig. 2. On the preoperative MRI, conus medullaris was observed on the sagittal T2-W series and it seemed to be fixed to the posterior at the level of $L 4$ vertebrae. Tense fibrotic band (arrowheads) extending from this level to coccygeal region was observed.

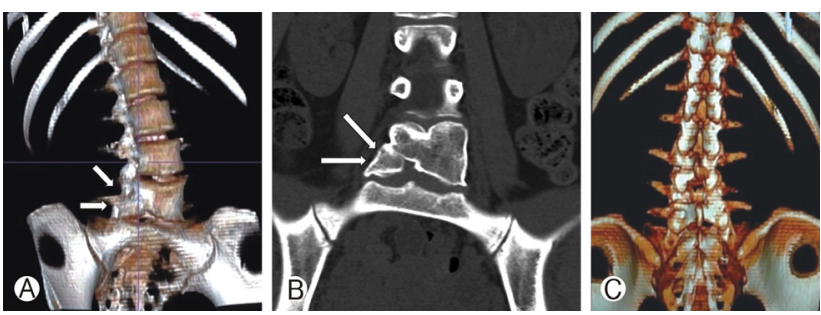

Fig. 3. L5 hemivertebra (arrows) on (A) 3D CT reconstruction; (B) coronal plane; (C) multiplanar reconstruction CT.

preparation, the tethered cord was observed and entered from the L5-S1 interspinous space under general anesthesia. The dura was observed as normal, macroscopically, and opened with the help of a microscope. The filum and roots were wound densely with arachnoid membrane and were adherent to the posterior dura. The thick filum was identified with the help of neuro-monitoring. All arachnoid adhesions were removed, and the filum terminale was cut. The dura was closed in accordance with accepted procedures. The patient was neurologically normal following the surgery (Fig. 4).

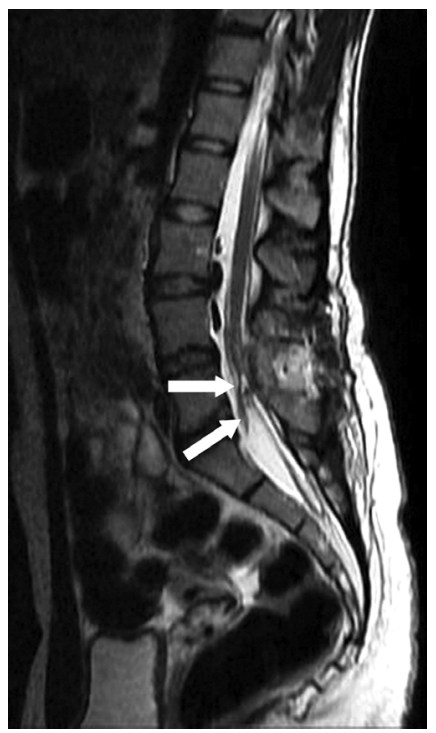

Fig. 4. On the postoperative MRI, liberalized fibrotic bands (arrows) showing an extension into the CSF in the spinal canal were observed on the sagiHal T2-weighted image.

\section{DISCUSSION}

An HV formation results from disruptions that occur during fetal life from a lack of formation of one of the two chondrification centers. It is observed in 5 of every 10,000 live births and is more common in girls ${ }^{5,6}$. In a study conducted by Eren et al. ${ }^{4)}$, an $\mathrm{HV}$ was found on the lumbar spine radiographs of only $4(0.27 \%)$ of 1,500 asymptomatic individuals with a mean age of 17 .

Gastrulation occurring in the embryonic period converts the bilaminar embryonic disc to a trilaminar structure containing ecto-, endo-, and mesoderm. Primitive vertebrae culminate in spinal structures with mesodermal-derived somites. On the $36^{\text {th }}$ day of embryological life, a rapid mesenchymal growth begins on both sides. On the $63^{\text {rd }}$ day, the small veins begin to occupy the center, and ossification begins. The failure of vertebral chondrification is due to vascularization and is not one-sided. In the second mechanism, the groups of cell pairs should show independent but synchronous development. Meanwhile, either a delay in the structure or no formation of the structure also creates the same pathology ${ }^{3)}$.

Different classifications exist in the literature. The classification by Touzet et al. ${ }^{11)}$ is based on two criteria: (1) the hemivertebra can be fused or is separate from the adjacent vertebra; and (2) the upper and lower adjacent vertebrae may or may not show transitional abnormality. Moe et al. ${ }^{8)}$ classified hemivertebra into four types (A to D) in relation to cranial or caudal adjacent vertebral bodies, which may be fully segmented, partially segmented, or unsegmented. The classifications, based on formation, include Type I (defect in formation), Type II (defect in segmentation), and Type III (mixed). 
Type I reflects a poor prognosis where the defects include progressive deformity and neurological disorders. Our case was consistent with Type II.

An association with concomitant congenital anomalies is very common in HV. A study conducted by Bollini et al. ${ }^{3)}$ reported that an $\mathrm{HV}$ was observed in the thoracic, lumbar, and lumbosacral regions in 45,35 , and $29 \%$ of cases, respectively. In the lumbar region, medullary anomalies (meningocele, syringomyelia, tethered spinal cord, myelocystocele, and lipoma) accompanied HV $13 \%$ of the time, genitourinary anomalies $24 \%$, and cardiac abnormalities $8 \%$.

In all age groups, Bollini et al. ${ }^{3)}$ detected intrathecal abnormalities in $15 \%$ of 75 cases with HV; McMaster et al. ${ }^{7}$ detected them in $15 \%$ of their series of 251 patients; Suh et al. ${ }^{10}$ in 31\% of 41 patients; Prahinski et al." in $30 \%$ of 30 patients; and Basu et al. ${ }^{2)}$ in $37 \%$ of 126 patients.

The L5 HV has an important feature. While the HV is growing, the L4 vertebrae shifts and causes bending. This causes progressive displacement of the lumbar spine. Normal righting reflexes lead to a secondary curvature, which starts from L4 in the distal and usually extends into the lower thoracic region. For this reason, surgery is recommended for these patients ${ }^{12}$. Our patient was sixteen years old. We did not think spinal surgery was indicated due to the existing spinal alignment, which did not lead to scoliosis, as mentioned in the literature. The radiological measurements reflected that an HV caused minimal scoliotic changes; therefore, we have followed the patient in our scoliosis clinic. We did perform bladder surgery, because the patient had frequent urinary tract infections and a hyperreflexic bladder was found on the urodynamic test. In the controls of the third month, neurological deficits were not observed, and her pain had decreased.

\section{CONCLUSION}

MRI is a good method for the detection of other underlying abnormalities. Concomitant congenital anomalies are common with an HV and can easily be detected via radiological testing. Neurological symptoms should be considered in regard to surgery, and scoliosis monitoring should be performed.

\section{REFERENCES}

1. Atabey C, Eroğlu A, Topuz AK, Velioğlu M, Demircan MN: Lumbar disc herniation in a patient with congenital vertebral body anomaly: a case report. Korean J Spine 11:245-248, 2014

2. Basu PS, Elsebaie H, Noordeen MH: Congenital spinal deformity: a comprehensive assessment at presentation. Spine (Phila Pa 1976) 27:2255-2259, 2002

3. Bollini G, Launay F, Docquier PL, Viehweger E, Jouve JL: Congenital abnormalities associated with hemivertebrae in relation to hemivertebrae location. J Pediatr Orthop B 19:90-94, 2010

4. Eren OT, Heybeli N, Okan E: The incidence of radiographic lumbar spine abnormalities in 1,500 asymptomatic military school candidates. Acta Orthop Traumatol Turc 35:130-134, 2001

5. Lee BJ, Sohn MJ, Han SR, Choi CY, Lee DJ, Kang JH: Analysis of risk factors and management of cerebrospinal fluid morbidity in the treatment of spinal dysraphism. J Korean Neurosurg Soc 54:225-231, 2013

6. Leung YL, Buxton N: Combined diastematomyelia and hemivertebra: a review of the management at a single centre. J Bone Joint Surg Br 87:1380-1384, 2005

7. McMaster MJ: Occult intraspinal anomalies and congenital scoliosis. J Bone Joint Surg Am 66:588-601, 1984

8. Moe JH, Winter RB, Bradford DS: Scoliosis and Other Spinal Deformities. Philadelphia: Saunders, 1978.

9. Prahinski JR, Polly DW Jr, McHale KA, Ellenbogen RG: Occult intraspinal anomalies in congenital scoliosis. J Pediatr Orthop 20:59-63, 2000

10. Suh SW, Sarwark JF, Vora A, Huang BK: Evaluating congenital spine deformities for intraspinal anomalies with magnetic resonance imaging. J Pediatr Orthop 21:525?531, 2001

11. Touzet P, Rigault P, Padovani JP: Hemivertebrae: classification, natural history and prognosis. Rev Chir Orthop Reparatrice Appar Mot 65:175-186, 1979

12. Winter RB, Burger EL: L5 hemivertebra resection and T12-S1 fusion in a 14-year-old female with a 36 -year follow-up. Spine (Phila Pa 1976) 37:E445-450, 2012 